\title{
Bacterial community shift and effects of the inclusion of a mixed psychrotrophic bacteria strain for sewage treatment in constructed wetland in winter seasons
}

\author{
xiaoyan xu ( $\sim$ 344637803@qq.com ) \\ Qufu Normal University \\ Jie Jiang ( $\nabla$ xuxiaoyan11232@163.com ) \\ Qufu Normal University \\ Zhinan Guo ( $\sim 1610180996 @ q q . c o m$ ) \\ Qufu Normal University \\ Lianglun Sun ( $\square$ xiaoyanxu11232@outlook.com ) \\ Qufu Normal University \\ Meizhen Tang ( $\nabla$ xuxiaoyan32112@163.com ) \\ Qufu Normal University
}

\section{Research Article}

Keywords: constructed wetlands, mixed psychrophilic strains, high-throughput sequencing technology, microbial diversity

Posted Date: September 20th, 2021

DOl: https://doi.org/10.21203/rs.3.rs-916866/v1

License: (c) (1) This work is licensed under a Creative Commons Attribution 4.0 International License.

Read Full License 


\section{Abstract}

The mechanism of wastewater treatment based on psychrophilic strains to improve the denitrification efficiency of constructed wetlands at low temperatures has already become a new hotspot. In this study, three mixed psychrophilic strains (Psychrobacter TM-1, Sphingobacterium TM-2 and Pseudomonas TM3) with high capacity of denitrification were added into a vertical-flow constructed wetlands (CWs), and the effect of the mixed strains on CWs sewage treatment was evaluated. The removal efficiency of chemical oxygen demand (COD), ammonia nitrogen $\left(\mathrm{NH}_{4}{ }^{+}-\mathrm{N}\right)$, total nitrogen (TN) and total phosphorus (TP) was quantified to establish the degradation kinetic model and determine the best dosage of the mixed strains. The effect mechanism of the mixed strains on indigenous microbial community and the change of sewage treatment performance in low temperature constructed wetlands was clarified by highthroughput sequencing technology. The results showed that the mixed strains can effectively remove the organic pollutants (nitrogen and phosphorus) and the optimum dosage of the mixed strain was $2.5 \%$, with average removal rates of 1.52, 2.12, 2.07 and 1.29 times than those of the control. Meanwhile, the dominant strains in the CWs were Proteobacteria (31.23-44.34\%), Chloroflexi (12.04-19.05\%), Actinobacteria (10.6-20.62\%), Acidobacteria (8.23-11.65\%), Firmicutes (2.23-15.95\%) and Bacteroidetes (4.01-18.9\%). These findings provide a basis for the removal of pollutants in constructed wetlands at low temperature.

\section{Introduction}

Constructed wetlands (CWs) are artificial constructed and controlled sewage treatment ecosystem that mimics the natural wetland, which mainly uses physical, chemical and biological technologies such as soil, artificial media, plants and microorganisms to purify sewage(Vymazal 2007; Farooqi, Basheer, and Chaudhari 2008; Breen 1990; Yu et al. 2020). For the advantages of simple process, good treatment effect and low operating cost, CWs has been widely used in many fields of wastewater treatment(Kivaisi 2001).

The composition and structure of microbial community are the main factors affected the effluent quality of constructed wetlands(Ibekwe, Grieve, and Lyon 2003; Kaushal, Wani, and Patil 2019; Hamdan, Salam, and Saikaly 2019). However, physical conditions such as low temperature affect the growth and activity of plants and population structure and metabolism of microorganisms in the CWs wastewater treatment process (Adams, Crump, and Kling 2010; Aromokeye et al. 2018; Zeng et al. 2019). The number of microorganisms and the metabolic efficiency of exogenous substances would be reduced under low temperature, so it is hard to form dominant microflora through natural selection, resulting in poor sewage treatment, or even substandard (Tang et al. 2018). Therefore, how to ensure the treatment effect of CWs under low temperature has become an urgent problem to be solved.

To date, research on the effect of bacteria organic pollutants removal under low temperature conditions in CWs is still in its infancy. The majority of the isolated strains were Psychrotrophic bacteria(Westlake et al. 1974; Atlas 1981; Järvinen, Melin, and Puhakka 1994; Yao et al. 2013; Vacková, Srb, and Stloukal 
2011), the molecular mechanism and related theory of its low temperature adaptability has also been studied. (Järvinen, Melin, and Puhakka 1994; Guo et al. 2010; Ma et al. 2009; Ying et al. 2010). Pei et al. (Pei, Yang, and Tian 2010) studied the effect of Bacillus.Subtilis FY99-01 on denitrification efficiency in wetlands and showed that the addition of microbial strain could effectively increase the nitrate removal efficiency in wetlands. Shao et al. (Shao, Pei, and Hu 2013) found that adding Paenibacillussp.XP1 to CWS could obviously improved the nitrogen removal efficiency at the temperature of $15 \sim 21^{\circ} \mathrm{C}$, and the concentration of ammonia nitrogen and total nitrogen in the effluent has also been reduced. Therefore, screening the dominant psychrophilic high-efficiency denitrification strains will provide more feasibility for the water treatment and remediation of the constructed wetland.

A single strain consequently causes unstable sewage treatment purification effect through poor viability. After entering the actual polluted environment, the survival and degradation capacity of dissociated microorganisms are easily affected by external factors, such as temperature, plants and so on. A large number of microorganisms will be lost, making it difficult to control its long-term treatment effect. As a result, it is found that the function of two or more microbial strains to combine the dominant strains has a better synergistic effect than a single strain(Tang et al. 2018; Ying et al. 2010). In previous research, Ying et al. (Ying et al. 2010) explored the ammonia nitrogen removal rates of the three cold-resistant strains into the constructed wetland system in cold areas to remove the winter wastewater. When the ambient temperature was $6^{\circ} \mathrm{C}$, the ammonia nitrogen removal rates of the three strains was $57.7 \%, 59.0 \%$ and $58.7 \%$ respectively at the concentration of $5 \%$ fungicide. Under the same condition, the removal rate was increased to $67.2 \%$ after using a mixture of the three strains. Therefore, the addition of mixed bacteria enhanced the denitrification effect of low temperature constructed wetlands. However, how to add cryogenic mixed microorganisms and the behavior of exogenous microorganisms in the environment and their impact on the environment is also an important issue related to the use of degradable bacteria, which has attracted more and more attention.

In this study, three kinds of psychrophilic strain were mixed into the constructed wetland according to a certain proportion, and a stable microecosystem was formed through the synergistic action of many kinds of low-temperature microorganisms. In order to give better play to its sewage treatment capacity and adaptability to nutrients and environmental conditions, construct a low-temperature microbial wastewater treatment kinetic model in constructed wetlands, using high-throughput sequencing technology, through different taxonomic levels of research. Analyze the community structure and composition of microorganisms in constructed wetlands, combined with the kinetic model of low temperature microbial wastewater treatment in constructed wetlands, better and more accurately reflect the effects of exogenous low-temperature mixed microorganisms on indigenous microbial diversity in constructed wetlands and more accurately analyze the mechanism of microbial pollutant removal in constructed wetlands, in order to improve the sewage treatment capacity and sustainable purification effect of constructed wetlands in winter. The purpose of this study is to provide theoretical basis and scientific support for the low-temperature sewage treatment of constructed wetlands, so as to provide some guidance and reference for the application and promotion of constructed wetlands in the cold conditions in the north. 


\section{Materials And Method}

\subsection{Design and operation of vertical-flow constructed wetland}

The constructed wetland (Fig. 1) was completed in March 2015. It was divided into five small-scale plot(SSP), each plot $\left(1 \mathrm{~m}^{2}\right)$ was designed with a vertical flow structure. The sewage of the vertical constructed wetland was evenly distributed from the surface of the block, vertically down, through the soil layer, slag layer and gravel layer to the bottom of the pool, and discharged through the collection pipe. Each plot consisted of three different particle size distribution layers: gravel in the bottom $150 \mathrm{~mm}$ depth (40 50mm diameter), slag in the middle $250 \mathrm{~mm}$ ( $5 \sim 10 \mathrm{~mm}$ diameter), and top 300 $\mathrm{mm}$ (in the downflow chamber) brown soil ( $0 \sim 4 \mathrm{~mm}$ diameter). And all pipes are stainless steel (diameter $75 \mathrm{~mm})$. In order to distribute the water evenly, the inlet pipe has a hole ( $5 \mathrm{~mm}$ diameter) on the bottom and spreads on the surface. Oriental cattail Typha orientalis Pres/ was planted in the sample plots. The hydraulic retention time was set to 5 days.

This influent water was taken from Qufu water co. LTD, and its parameters were shown in Table 1.

Table. 1 Parameters of Inflow of the MSP

\begin{tabular}{|lll|}
\hline Index & Influent & Effluent \\
\hline $\mathrm{pH}$ & $7.2 \sim 7.8$ & $7.0 \sim 7.4$ \\
\hline temperature $\left({ }^{\circ} \mathrm{C}\right)$ & $4 \sim 12$ & $6 \sim 12$ \\
\hline $\mathrm{DO}\left(\mathrm{mg} \cdot \mathrm{L}^{-1}\right)$ & $3.4 \sim 3.8$ & $0.2 \sim 0.4$ \\
\hline $\mathrm{TSS}\left(\mathrm{mg} \cdot \mathrm{L}^{-1}\right)$ & $2.1 \sim 2.5$ & not detected \\
\hline $\mathrm{COD}\left(\mathrm{mg} \cdot \mathrm{L}^{-1}\right)$ & $170.5 \sim 200.9$ & not detected \\
\hline $\mathrm{NH}{ }_{4}{ }^{+} \mathrm{N}\left(\mathrm{mg} \cdot \mathrm{L}^{-1}\right)$ & $46.8 \sim 50.8$ & not detected \\
\hline $\mathrm{TN}\left(\mathrm{mg} \cdot \mathrm{L}^{-1}\right)$ & $81.7 \sim 90.9$ & not detected \\
\hline $\mathrm{TP}\left(\mathrm{mg} \cdot \mathrm{L}^{-1}\right)$ & $12.8 \sim 14.2$ & not detected \\
\hline
\end{tabular}

DO: dissolved oxygen; TSS: total suspended solids; COD: chemical oxygen demand; $\mathrm{NH}_{4}{ }^{+} \mathrm{N}$ : ammonium nitrogen; TN: total nitrogen; TP: total phosphorous.

The preparation of mixed psychrophilic strains suspension囚The Psychrobacter TM-1 (GenBank acceptance number KR083014), Sphingobacterium TM-2 (GenBank acceptance number KR083015) and Pseudomonas TM-3(GenBank acceptance number KR083016) were incubated in the LB liquid culture 
medium until their absorbance reaching $1.2 \sim 1.6$. Then centrifuged in the centrifuge, discard the supernatant, and dilute the three kinds of bacteria with physiological saline. Repeat this process three times to remove nutrients from the culture medium. Finally, the absorbance of the solution was adjusted to 1.2 with normal saline water, and then the bacterial solution was mixed according to the volume ratio of 1:1:1. In early November 2018 (temperature of the water was $4 \sim 12^{\circ} \mathrm{C}$ ), bacterium suspension of mixed psychrophilic strains $\left(4.4 \times 10^{9} \mathrm{~mL}^{-1}\right)$ was injected into the vertical-flow constructed wetland system, with $0.5 \sim 5.0 \%$ volume ratio of sewage, and the concentration was $B, C, D, E$ from low to high. And also there was a control treatment which called $A$ that does not culture any psychrophilic bacteria. Then, the concentrations change of $\mathrm{COD}, \mathrm{NH}_{4}{ }^{+} \mathrm{N}, \mathrm{TN}$ and TP were monitored for five months in the effluent. Meanwhile, the soil samples of five plots were collected by the plum shaped sampling method, respectively, packed in a sterile sealed bag for microbial diversity analysis.

All the parameters of water were analyzed according to the standard methods (APHA, 1998). To do the statistical analysis and draw on the determination about the results by using software Origin 8.6 and SPSS19.

\subsection{Microbial DNA extraction and sequencing}

Microbial genomic DNA was isolated using a PowerSoil DNA Isolation Kit (MoBio Laboratories, Carlsbad, CA) kit. DNA products were evaluated by electrophoresis in $1 \%$ agarose gels. Nanodrop was used to test the quality and concentration of DNA. The V3-V4 hypervariable regions of the 16S rRNA gene were subjected to high-throughput sequencing by Beijing Auwigene Tech, Ltd (Beijing, China) using the Illumina Miseq Reagent Kit v3 (600 cycle)(PE300) sequencing platform (Illumina, Inc., CA, USA). And raw sequencing data were processed by Beijing Auwigene Tech, Ltd. (Beijing, China) using the pipeline tools QIIME(http://qiime.org/scripts/assign_taxonomy.html).

\section{Monod Kinetic Model}

The denitrification efficiency of mixed psychrophilic bacteria in vertical flow constructed wetland was simulated by simplified Monod kinetic model (Saeed and Sun 2011). It is assumed that the degradation of pollutants follows Monod kinetics, and the vertical flow constructed wetland is a continuous stirred reactor (CSTR). Therefore, the Monod equation can be expressed as:

$$
K=\frac{q\left(C_{\text {in }}-C_{\text {out }}\right)\left(C_{\text {half }}+C_{\text {out }}\right)}{C_{\text {out }}}
$$

In the formula above, $\mathrm{K}$ is the constant removal rate of the largest area $\left(\mathrm{g} \cdot\left(\mathrm{m}^{2} \cdot \mathrm{d}\right)^{-1}\right)$, $\mathrm{q}$ is the hydraulic loading rate $\left(\mathrm{m} \cdot \mathrm{d}^{-1}\right), C_{\text {in }}$ is the influent nitrogen concentration $\left(\mathrm{mg} \cdot \mathrm{L}^{-1}\right), C_{\text {out }}$ is the effluent nitrogen concentration (mg. $\left.\mathrm{L}^{-1}\right)$, and $C_{\text {half }}$ is the semi-saturation constant of the limiting factor. 


\section{Results And Analysis}

\subsection{Effect of mixed strains in different dosages on sewage treatment}

After running continuously for five months, the removal effects of mixed psychrophilic bacteria suspension with different dosage on the sewage index of vertical flow wetland is shown in Fig. 2.

The results show that the mixed psychrophilic bacteria suspension in the vertical flow system with different dosages had an excellent effect on the treatment of sewage in winter. The removal efficiencies of COD, $\mathrm{NH}_{4}{ }^{+}-\mathrm{N}, \mathrm{TN}$ and TP increased with the dosage $(0.5 \sim 5.0 \%)$. When the dosage increased from $1.5-5.0 \%$, the pollutants removal rate significantly increased; however, the pollutants removal rate was very little increased as the dosage increased from 2.5-5.0\%. Although the pollutants removal rate of 5.0\% dosage is the highest, the increase is not obvious, and excess bacteria were used; therefore, considering the operating cost, the optimal dosage should be $2.5 \%$.

When the dosage is $2.5 \%$, the removal efficiency of the four indexes in the sewage by the mixed psychrophilic bacteria in the vertical flow system is significantly improved, and the removal rates of COD, $\mathrm{NH}_{4}{ }^{+}-\mathrm{N}$, TN and TP were between $84.15 \sim 87.06 \%, 89.79 \sim 92.28 \%, 85.55 \sim 89.41 \%$ and $96.68 \sim 97.11 \%$, respectively, and the average removal rates were 1.52, 2.12, 2.07 and 1.29 times than those of the control. Moreover, the average concentrations of $\mathrm{COD}, \mathrm{NH}_{4}{ }^{+}-\mathrm{N}, \mathrm{TN}$, and TP in the effluent were 42.62, 4.26, 11.14 and $0.42 \mathrm{mg} \cdot \mathrm{L}^{-1}$, respectively, which has reached the first grade of Chinese national discharge standard of pollutants for municipal wastewater treatment plant (GB18918-2002).

Compared to the single bacterium of Pseudomonas flava WD-3, the optimal dosage was greatly reduced from $6.0 \%$ to $2.5 \%$, and the hydraulic retention time was shortened (HRT) from 10 days to 5 days, but the average removal rates of $\mathrm{NH}_{4}{ }^{+} \mathrm{N}$ and TP were $6.4 \%$ and $6.5 \%$ higher, as the COD removal rate is consist with it(Tang et al. 2014), and the removal performance is very stable. Thereby it increased the amount of sewage treatment and reducing the cost of sewage purification. At the same time, the results fully shown that there is a mutually beneficial relationship between the bacteria, and the coordination of various microorganisms, so that pollutants can be better removed. Liu's studies have shown that the mixture of bacillus subtilis, lactobacillus lactobacillus and lactobacillus plantarum had higher removal rate of nitrogen and COD than the single bacteria treatment systems(K. F. Liu et al. 2010). Similarly, Moussavi \& Heidarizad indicated that the addition of mixed bacteria shortens the acclimation time and aeration time of the reactor, improves the processing capacity and effect of the reactor, and enhances the impact load resistance and stability of the system(Moussavi and Heidarizad 2011). González added the selected mixed bacteria to stirred tank and fluidized-bed bioreactors directionally, the result showed that the time of domestication and aeration was shorten and the disposal ability and the effect of continuous process were improved, especially the COD removal efficiency was more than $90 \%$ (González et al. 2001). 
Moreover, these studies also indicated the possibility of the utilization of the mixed bacteria to dispose the low-temperature sewage

Within the scope of optimal dosage, the statistical analysis of dosage and the purification effect of pollutants showed that the dosage of mixed Psychrotrophic bacteria was significantly positive correlated with the removal rate of COD, $\mathrm{NH}_{4}{ }^{+}-\mathrm{N}, \mathrm{TN}$ and TP of sewage, and the correlation coefficients were $0.9870 * \star, 0.9844 * *, 0.9422^{* *}, 0.9742 * *$, respectively, $* * p<0.01$.

\subsection{Simulation and validation of the model}

Compared with the pseudo-first order kinetic model, the Monod kinetic model was more consistent with the actual situation of microbial treatment pollutants in water treated by microorganisms, so it is more suitable for the microorganism-led pollutant degradation process (Mitchell and McNevin 2001). When the above-mentioned Monod model was used to simulate the decontamination rate of mixed bacteria in vertical flow wetland, the $C_{\text {half }}$ of this model for COD, $\mathrm{NH}_{4}{ }^{+} \mathrm{N}$, TN and TP were $20 \mathrm{mg} \cdot \mathrm{L}^{-1}, 1.0 \mathrm{mg} \cdot \mathrm{L}^{-1}$ (Henze, Grady Jr., and Gujer 1987), $2.0 \mathrm{mg} \cdot \mathrm{L}^{-1}$ (Giese, Khalil, and Ulery 1978) and $0.2 \mathrm{mg} \cdot \mathrm{L}^{-1}$ (Henze et al. 1995). Therefore, three parameters were introduced to evaluate the merit of the model, as shown below:

efficient determination:

$$
R^{2}=\frac{\left[\sum_{i=1}^{N}\left(X_{i}-\bar{X}\right)\left(Y_{i}-\bar{Y}\right)\right]^{2}}{\sum_{i=1}^{N}\left(X_{i}-\bar{X}\right)^{2} \sum_{i=1}^{N}\left(Y_{i}-\bar{Y}\right)^{2}}
$$

Relative root-mean-square error:

$$
\text { RRMES }=\sqrt{\frac{1}{N} \sum_{i=1}^{N}\left(Y_{i}-\hat{Y}\right)^{2}} / \hat{Y}
$$

(value range: $0-\infty)(3)$

Model efficiency:

$$
M E=1-\sum_{i=1}^{N}\left(Y_{i}-\hat{Y}\right)^{2} / \sum_{i=1}^{N}\left(Y_{i}-\bar{Y}\right)^{2}
$$

(value range: $-\infty-0)(4)$

Where ${ }^{X_{i}}, Y_{i}$ were the pollutant concentrations in the inflow and outflow at different time, respectively; $\bar{X}, \bar{Y}$ were the mean of pollutant concentrations in the inflow and outflow, respectively; and ${ }^{\hat{Y}}$ was the predictive value.

Simplified Monod model of the relationship between $f\left(C_{\text {in }}, C_{\text {out }}, q\right)$ and $C_{\text {out }}$ is shown in Fig. 3. Regression fitting line slope of the maximum removal rate of pollutants $\left(K, g \cdot \mathrm{m}^{-2} \cdot \mathrm{d}^{-1}\right)$; and the Statistical parameters, such as $\mathrm{R}^{2}$, RRMSE, and ME wereR2, RRMSE and ME were used to represent the deviation between the measured values of pollutants and the predicted values of the model.

The relationship between in the simplified Monod model were revealed The slope of the regression fitting line is the maximum removal rate of pollutants); statistical parameter applied to indicate the deviation 
between the measured values of pollutants and the predicted values of the model. The dotted line represents $95 \%$ confidence interval, including the real regression fitting line.

Figure 3 shown, the statistical parameter $\mathrm{R}^{2}$ of $\mathrm{COD}, \mathrm{NH}_{4}{ }^{+}-\mathrm{N}, \mathrm{TN}$ and TP were $0.6304,0.9499,0.9286$ and 0.7739 with different dosages of mixed bacteria, both RRMES and ME were well within the expected range. The Monod model was helpful to comprehend the relationship between constructed wetland volume and pollutant concentration, and was used to collect data and run the model("Major Subject : Environmental Engineering" 2011). From the collected data, that showed a better fit between the predicted and experimental values of pollutants removal by mixed bacteria in the vertical flow wetland. Monod described the degradation rate of pollutants as the only source of energy or carbon source, that is, the biomass produced by the consumption of each unit of carbon source(Schobinger 1976). Similarly, in the case of controlling the concentration of pollutants, Monod can also describe the degradation rate by the dosage of different microorganisms. Therefore, the simplified Monod model accurately predicted the removal efficiency of pollutants.

\subsection{Bacterial community structure analysis}

\subsubsection{Bacterial community shift in phylum level}

For 5 samples from different vertical flow systems, a total of 879,791 valid sequences were obtained after quality control. The clean sequences for A, B, C, D and E were 99,868, 266,285, 38,445, 54,430 and 46,861 , respectively. The length of these valid sequences was principally about $400 \sim 440 \mathrm{bp}$, accounting for $99.6 \%$ of the total number of valid sequences. The mean length of these valid sequences was nearly 420 bp.

The bacterial sequences obtained from five groups were classified into 5,863 OTUs, of which the OTUs cluster was divided into 13 phyla. As demonstrated in Fig. 4, the main phyla in the five wetland soil samples were Proteobacteria (31.23-44.34\%), Chloroflexi (12.04-19.05\%), Actinobacteria (10.6-20.62\%), Acidobacteria (8.23-11.65\%), Firmicutes (2.23-15.95\%) and Bacteroidetes (4.01-18.9\%), and the proportion of these bacteria generally shows a decreasing trend. Gemmatimonadetes, Cyanobacteria, Nitrospirae, Verrucomicrobia, Planctomycetes, Parcubacteria and Saccharibacteria were also emerged in most biosamples at a relatively low abundance.

The six dominant phyla of the five samples were Proteobacteria, Chloroflexi, Actinobacteria, Acidobacteria, Firmicutes and Bacteroidetes, which accounted for $83.36-89.88 \%$ of the tested phyla. The microbial changes in vertical flow systems with different concentration gradients were obvious. Many strains in Proteobacteria, Firmicutes and Bacteroidetes have been proved to have good purification effect on organic pollutants in sewage and have better ability of nitrogen and phosphorus removal(Peralta, Ahn, and Gillevet 2013). As shown in Fig. 4, the proportion of Proteobacteria, Chloroflexi and Actinobacteria in sample $D$ and $E$ was similar, which corresponds to the results that the treatment effect of sewage treatment in these two systems is roughly the same and better. Proteobacteria are the main force of sewage treatment, and the majority of Proteobacteria are denitrifying bacteria, among which $a-$ 
Proteobacteria is the main class of cold resistant bacteria and has a strong ability to remove nitrogen elements. $\beta$ - Proteobacteria can use organic matter to transform into $\mathrm{NH}_{3}$ and other substances, and then remove organic pollutants in sewage(Juretschko et al. 2002; Shapleigh 2011).The proportion of Proteobacteria in sample A was significantly higher than that of other vertical flow systems, which may be the Psychrobacter TM-1 (GenBank acceptance number KR083014) and Pseudomonas TM-3( GenBank acceptance number KR083016) in the three strains are both Proteobacteria, which compete with other strains of Proteobacteria, and inhibit the growth of other strains, and then leads to the poor effect of sewage treatment. Proteobacteria always maintains a high relative abundance $(>31.23 \%)$ in each vertical flow wetland(Costa et al. 2014), which is beneficial to the removal of organic matter and nutrients, which is consistent with the results of Sun and other studies(Sun et al. 2016). The sewage treatment effect of sample $D$ and $E$ is better than others, and the sewage treatment effect of sample $C$ is obviously lower than that of the former two. This is mainly because it contains more Actinobacteria (20.63\%), which inhibits the growth of other bacteria conducive to nitrogen and phosphorus removal (Ramirez, Craine, and Fierer 2012). The number of Firmicutes bacteria in sample $\mathrm{E}(15.95 \%)$ was significantly more than that of the other four samples (2.23-10.04\%). Compared with sample A, it was found that sample E had the greatest inhibitory effect on the diversity of indigenous microorganisms in constructed wetlands, and the wetland sewage treatment effect of sample $\mathrm{E}$ was the best, indicating that some bacteria in Firmicutes enhanced the effect of nitrogen and phosphorus removal in vertical flow systems. It has been found that Firmicutes can be involved in the decomposition of organic matter, which can decompose organic matter into inorganic matter and provide nutrients for microorganisms and plants, which plays an important role in sewage treatment in constructed wetlands(Wirth et al. 2012; Lim, Chiam, and Wang 2014).What's more, The sewage treatment effect of sample $C$ is obviously lower than that of the former two, mainly because it contains more actinomycetes $(20.63 \%)$, which inhibits the growth of other bacteria conducive to nitrogen and phosphorus removal (Ramirez, Craine, and Fierer 2012).

\subsection{Bacterial community shift in genus level}

The relative ratio of bacterial composition at genus level was shown in Fig. 5 . The 20 genera with the richest species were compared with the sequencing sequences, and the heatmap of different colors were constructed. The change of relative richness can be observed intuitively through the change of color in the heatmap, and the abundance differences between different genera or the same genus in different samples can be provided in different samples (Jami et al. 2013). The vertical flow systems where the samples are located also have high diversity at the genus level. And the main bacteria are Anaerobacillus, Bacillus, Luedemannella, Bryobacter, lamia, uncultured,Azohydromonas, Geobacter, Caenimonas, Haliangium, H16, Streptomyces, RB41, Trichococcus, Macellibacteroides, Anaerolinea, Gaiella, Roseiflexus. According to the analysis of the Fig. 5, the abundance of Geobacter, Haliangium, Azohydromonas and Anaeromyxobacter in sample A was significantly higher than that of the other four samples, Azohydromonas were related with nitrogen cycle, including nitrification, denitrification and nitrogen fixation(McDonald et al. 2015; Lin et al. 2018). The abundance of lamia, Anaerolinea and Luedemannella in sample $\mathrm{C}$ was higher than that of other samples. Luedemannella is related to the removal of organic pollutants, belongs to Actinobacteria and may inhibit the growth of denitrifying 
bacteria.(Ara and Kudo 2007).And Trichococcus, Macellibacteroides and Roseiflexus were ubiquitous in sample B. Trichococcus(J.-R. Liu et al. 2002) is related to sludge bulking, which is little in sample E and D. The increase of these bacteria may inhibit the growth of other cold-tolerant bacteria with good sewage treatment effect, and as a result, the effect of wetland sewage treatment is poor. The relative abundance of Bacillus, Anaerobacillus, Streptomyces and RB41 in sample D and E is significantly richer than that in other samples. This directly leads to the significant improvement of the sewage treatment effect of the wetland where the sample $E$ and $D$ are located. $R B 41$ was reported to be effected on the removal of pollutants such as phosphorus(Zhang, Xu, and Zhu 2018), meanwhile, Bacillus, belonging to the Firmicutes, not only has the function of degrading COD, but also has the ability of nitrate reduction(Pei, Yang, and Tian 2010),indicating that Bacillus can stably exist and maintain a certain metabolic ability in wetlands, and work together with other heterotrophic and autotrophic bacteria to complete the removal of COD and nitrogen from domestic sewage. Anaerobacillus (C. Liu et al. 2015) is a heterotrophic denitrifying microorganism, which can reduce nitrate and release molecular nitrogen to achieve the purpose of nitrogen removal. It can be seen that when three mixed psychrophilic strains, namely, Psychrobacter, Sphingobacterium and Pseudomonas, were added to the Vertical-flow Constructed Wetlands, it caused significant changes in the structure and number of indigenous microorganisms. Meanwhile, when the dosage of mixed suspension of three psychrophilic strains was $2.5 \%$, the mixed bacterial suspension of the three psychrophilic strains played a certain role in promoting the growth of Bacillus, Anaerobacillus, Streptomyces and RB41 in the Vertical-flow Constructed Wetlands. The sewage treatment effect and microbial community analysis of each system showed that Bacillus, Anaerobacillus, Streptomyces and RB41 play a decisive role in improving the removal efficiency of nitrogen, phosphorus and Organic pollutant. The addition of this kind of mixed bacteria suspension is beneficial to improve the treatment capacity of the Vertical-flow Constructed Wetlands to sewage, including nitrogen, phosphorus and organic matter, under the condition of low temperature.

\section{Conclusion}

This study investigated the effect of pollutant removal and the migration of bacterial community, and explained the pollutant removal mechanism from the point of view of microorganisms. The mixed strains can effectively remove the organic pollutants (nitrogen and phosphorus) and the optimum dosage of the mixed strain was $2.5 \%$,with average removal rates of 1.52, 2.12, 2.07 and 1.29 times than those of the control. Proteobacteria, Chloroflexi, Actinobacteria, Acidobacteria, Firmicutes and Bacteroidetes were dominant bacteria in Vertical flow constructed wetland. three mixed psychrophilic strains was propitious to enrich Bacillus, Anaerobacillus, Streptomyces and RB41, which leads to the improvement of the effect of Vertical flow sewage treatment. The purpose of this study is to enrich bacterial information and promote the development and application of wetland sewage treatment system.

\section{Declarations}

Ethics approval and consent to participate. Not applicable. 
Consent for publication. Not applicable.

Availability of data and material. All data generated or analysed during this study are included in this published article [and its supplementary information files].

Competing interests. None.

Funding. This work was supported by the National Natural Science Foundation of China [grant numbers31700433, 31672314].

Acknowledgement. The authors gratefully thank the financial support provided by the National Natural Science Foundation of China (No. 31700433; No. 31672314).

\section{Conflicts of interest}

The authors declare that there are no conflicts of interest regarding the publication of this article.

\section{References}

Adams, Heather E, Byron C Crump, and George W Kling. 2010. "Temperature Controls on Aquatic Bacterial Production and Community Dynamics in Arctic Lakes and Streams." Environmental Microbiology 12 (5): 1319-33. https://doi.org/10.1111/j.1462-2920.2010.02176.x.

Ara, Ismet, and Takuji Kudo. 2007. "Luedemannella Gen. Nov., a New Member of the Family Micromonosporaceae and Description of Luedemannella Helvata Sp. Nov. and Luedemannella Flava Sp. Nov." Journal of General and Applied Microbiology 53 (1): 39-51. https://doi.org/10.2323/jgam.53.39.

Aromokeye, David A, Tim Richter-Heitmann, Oluwatobi E Oni, Ajinkya Kulkarni, Xiuran Yin, Sabine Kasten, and Michael W Friedrich. 2018. "Temperature Controls Crystalline Iron Oxide Utilization by Microbial Communities in Methanic Ferruginous Marine Sediment Incubations." Frontiers in Microbiology 9 (October): 1-13. https://doi.org/10.3389/fmicb.2018.02574.

Atlas, R. M. 1981. "Microbial Degradation of Petroleum Hydrocarbons: An Environmental Perspective." Microbiological Reviews 45 (1): 180-209. https://doi.org/10.1128/mmbr.45.1.180-209.1981.

Breen, Peter F. 1990. "A Mass Balance Method for Assessing the Potential of Artificial Wetlands for Wastewater Treatment." Water Research 24 (6): 689-97. https://doi.org/10.1016/0043-1354(90)90024-Z.

Costa, Maria Cristina Monteiro S., Luciana Carvalho, Cintia Dutra Leal, Marcela França Dias, Karoline L. Martins, Guilherme Brugger Garcia, Isabella Daldegan Mancuelo, et al. 2014. "Impact of Inocula and Operating Conditions on the Microbial Community Structure of Two Anammox Reactors." Environmental Technology (United Kingdom) 35 (14): 1811-22. https://doi.org/10.1080/09593330.2014.883432. 
Farooqi, I H, Farrukh Basheer, and Rahat Jahan Chaudhari. 2008. "Constructed Wetland System (CWS) for Wastewater Treatment." Proceedings of Taal 2007: The World Lake Conference, no. May 2014: 1004-9.

Giese, J. H., H. M. Khalil, and D. L. Ulery. 1978. "Multiparameter Families of Difference Approximations for the First Initial Boundary Value Problem for the Heat Equation in an Arbitrary Region." Journal of Engineering Mathematics 12 (2): 97-114. https://doi.org/10.1007/BF00043213.

González, G., M. G. Herrera, M. T. García, and M. M. Peña. 2001. “Biodegradation of Phenol in a Continuous Process: Comparative Study of Stirred Tank and Fluidized-Bed Bioreactors." Bioresource Technology 76 (3): 245-51. https://doi.org/10.1016/S0960-8524(00)00092-4.

Guo, Jingbo, Jihua Wang, Di Cui, Li Wang, Fang Ma, Chein Chi Chang, and Jixian Yang. 2010. "Application of Bioaugmentation in the Rapid Start-up and Stable Operation of Biological Processes for Municipal Wastewater Treatment at Low Temperatures." Bioresource Technology 101 (17): 6622-29. https://doi.org/10.1016/j.biortech.2010.03.093.

Hamdan, Hamdan Z., Darine A. Salam, and Pascal E. Saikaly. 2019. "Characterization of the Microbial Community Diversity and Composition of the Coast of Lebanon: Potential for Petroleum Oil Biodegradation." Marine Pollution Bulletin 149 (April 2019): 110508. https://doi.org/10.1016/j.marpolbul.2019.110508.

Henze, M., W. Gujer, T. Mino, T. Matsuo, M. C. Wentzel, and G. v.R. Marais. 1995. "Wastewater and Biomass Characterization for the Activated Sludge Model No. 2: Biological Phosphorus Removal." Water Science and Technology 31 (2): 13-23. https://doi.org/10.1016/0273-1223(95)00176-N.

Henze, M, C P L Grady Jr., and W Gujer. 1987. "A General Model for Single-Sludge Wastewater Treatment Systems." Water Research 21 (5): 505-15.

Ibekwe, A Mark, Catherine M Grieve, and Stephen R Lyon. 2003. "Characterization of Microbial Community in Constructed Dairy Wetland.Pdf." Applied and Environmental Microbiology 69 (9): 5060-69. https://doi.org/10.1128/AEM.69.9.5060.

Jami, Elie, Adi Israel, Assaf Kotser, and Itzhak Mizrahi. 2013. "Exploring the Bovine Rumen Bacterial Community from Birth to Adulthood." ISME Journal 7 (6): 1069-79.

https://doi.org/10.1038/ismej.2013.2.

Järvinen, Kimmo T., Esa S. Melin, and Jaakko A. Puhakka. 1994. "High-Rate Bioremediation of Chlorophenol-Contaminated Groundwater at Low Temperatures." Environmental Science Technology 28 (13): 2387-92. https://doi.org/10.1021/es00062a025.

Juretschko, Stefan, Alexander Loy, Angelika Lehner, and Michael Wagner. 2002. "The Microbial Community Composition of a Nitrifying-Denitrifying Activated Sludge from an Industrial Sewage 
Treatment Plant Analyzed by the Full-Cycle RRNA Approach." Systematic and Applied Microbiology 25 (1): 84-99. https://doi.org/10.1078/0723-2020-00093.

Kaushal, Manoj, Suhas P. Wani, and Mukund D. Patil. 2019. "Harnessing Microbial Potential for Wastewater Treatment in Constructed Wetlands." Sustainable Green Technologies for Environmental Management, 271-82. https://doi.org/10.1007/978-981-13-2772-8_14.

Kivaisi, Amelia K. 2001. "The Potential for Constructed Wetlands for Wastewater Treatment and Reuse in Developing Countries: A Review." Ecological Engineering 16 (4): 545-60. https://doi.org/10.1016/S09258574(00)00113-0.

Lim, Jun Wei, Jun An Chiam, and Jing Yuan Wang. 2014. "Microbial Community Structure Reveals How Microaeration Improves Fermentation during Anaerobic Co-Digestion of Brown Water and Food Waste." Bioresource Technology 171: 132-38. https://doi.org/10.1016/j.biortech.2014.08.050.

Lin, Zhenyue, Liuying Wang, Mingliang Chen, and Jianming Chen. 2018. "The Acute Transcriptomic Response of Coral-Algae Interactions to PH Fluctuation." Marine Genomics 42 (September): 32-40. https://doi.org/10.1016/j.margen.2018.08.006.

Liu, Chunshuang, Chaocheng Zhao, Aijie Wang, Yadong Guo, and Duu Jong Lee. 2015. "Denitrifying Sulfide Removal Process on High-Salinity Wastewaters." Applied Microbiology and Biotechnology 99 (15): 6463-69. https://doi.org/10.1007/s00253-015-6505-5.

Liu, Jian-Rong, Ralph S Tanner, Peter Schumann, Norbert Weiss, Christine A McKenzie, Peter H Janssen, Elizabeth M Seviour, Paul A Lawson, Toby D Allen, and Robert J Seviour. 2002. "Emended Description of the Genus Trichococcus, Description of Trichococcus Collinsii Sp. Nov., and Reclassification of Lactosphaera Pasteurii as Trichococcus Pasteurii Comb. Nov. and of Ruminococcus Palustris as Trichococcus Palustris Comb. Nov. in the Lo." International Journal of Systematic and Evolutionary Microbiology 52 (4): 1113-26. https://doi.org/10.1099/00207713-52-4-1113.

Liu, Kuan Fu, Chiu Hsia Chiu, Ya Li Shiu, Winton Cheng, and Chun Hung Liu. 2010. "Effects of the Probiotic, Bacillus Subtilis E20, on the Survival, Development, Stress Tolerance, and Immune Status of White Shrimp, Litopenaeus Vannamei Larvae." Fish and Shellfish Immunology 28 (5-6): 837-44. https://doi.org/10.1016/j.fsi.2010.01.012.

Ma, Fang, Jing bo Guo, Li jun Zhao, Chein chi Chang, and Di Cui. 2009. "Application of Bioaugmentation to Improve the Activated Sludge System into the Contact Oxidation System Treating Petrochemical Wastewater." Bioresource Technology 100 (2): 597-602. https://doi.org/10.1016/j.biortech.2008.06.066.

"Major Subject: Environmental Engineering." 2011, no. August.

McDonald, Ryan, Fan Zhang, Joy E.M. Watts, and Harold J. Schreier. 2015. "Nitrogenase Diversity and Activity in the Gastrointestinal Tract of the Wood-Eating Catfish Panaque Nigrolineatus." ISME Journa/ 9 
(12): 2712-24. https://doi.org/10.1038/ismej.2015.65.

Mitchell, Cynthia, and Dennis McNevin. 2001. "Alternative Analysis of BOD Removal in Subsurface Flow Constructed Wetlands Employing Monod Kinetics." Water Research 35 (5): 1295-1303.

https://doi.org/10.1016/S0043-1354(00)00373-0.

Moussavi, Gholamreza, and Mahdi Heidarizad. 2011. "The Performance of SBR, SCR, and MSCR for Simultaneous Biodegradation of High Concentrations of Formaldehyde and Ammonia." Separation and Purification Technology 77 (2): 187-95. https://doi.org/10.1016/j.seppur.2010.11.028.

Pei, Yuansheng, Zhifeng Yang, and Binghui Tian. 2010. "Nitrate Removal by Microbial Enhancement in a Riparian Wetland." Bioresource Technology 101 (14): 5712-18.

https://doi.org/10.1016/j.biortech.2010.02.005.

Peralta, Rita M., Changwoo Ahn, and Patrick M. Gillevet. 2013. "Characterization of Soil Bacterial Community Structure and Physicochemical Properties in Created and Natural Wetlands." Science of the Total Environment 443: 725-32. https://doi.org/10.1016/j.scitotenv.2012.11.052.

Ramirez, Kelly S., Joseph M. Craine, and Noah Fierer. 2012. "Consistent Effects of Nitrogen Amendments on Soil Microbial Communities and Processes across Biomes." Global Change Biology 18 (6): 1918-27. https://doi.org/10.1111/j.1365-2486.2012.02639.x.

Saeed, Tanveer, and Guangzhi Sun. 2011. "Kinetic Modelling of Nitrogen and Organics Removal in Vertical and Horizontal Flow Wetlands." Water Research 45 (10): 3137-52.

https://doi.org/10.1016/j.watres.2011.03.031.

Schobinger, Juan. 1976. “Current Research.” American Antiquity 41 (2): 213-35. https://doi.org/10.1017/S0002731600092453.

Shao, Yuanyuan, Hai yan Pei, and Wen rong Hu. 2013. "Nitrogen Removal by Bioaugmentation in Constructed Wetlands for Rural Domestic Wastewater in Autumn." Desalination and Water Treatment 51 (34-36): 6624-31. https://doi.org/10.1080/19443994.2013.791787.

Shapleigh, James P. 2011. "Oxygen Control of Nitrogen Oxide Respiration, Focusing on a-Proteobacteria." Biochemical Society Transactions 39 (1): 179-83. https://doi.org/10.1042/BST0390179.

Sun, Yanmei, Yue xiao Shen, Peng Liang, Jizhong Zhou, Yunfeng Yang, and Xia Huang. 2016. "Multiple Antibiotic Resistance Genes Distribution in Ten Large-Scale Membrane Bioreactors for Municipal Wastewater Treatment." Bioresource Technology 222: 100-106.

https://doi.org/10.1016/j.biortech.2016.09.117.

Tang, Meizhen, Zhengtao Li, Yuewei Yang, Junfeng Chen, and Jie Jiang. 2018. "Effects of the Inclusion of a Mixed Psychrotrophic Bacteria Strain for Sewage Treatment in Constructed Wetland in Winter Seasons." Royal Society Open Science 5 (4). https://doi.org/10.1098/rsos.172360. 
Tang, Meizhen, Fengfeng Zhang, Shumin Yao, Yuling Liu, and Junfeng Chen. 2014. "Application of Pseudomonas Flava WD-3 for Sewage Treatment in Constructed Wetland in Winter Application of Pseudomonas Flava WD-3 for Sewage Treatment in Constructed Wetland in Winter," no. June 2016. https://doi.org/10.1080/21622515.2014.983183.

Vacková, Lenka, Martin Srb, and Radek Stloukal. 2011. "Bioresource Technology Comparison of Denitrification at Low Temperature Using Encapsulated Paracoccus Denitrificans, Pseudomonas Fluorescens and Mixed Culture" 102: 4661-66. https://doi.org/10.1016/j.biortech.2011.01.024.

Vymazal, Jan. 2007. "Removal of Nutrients in Various Types of Constructed Wetlands." Science of the Total Environment 380 (1-3): 48-65. https://doi.org/10.1016/j.scitotenv.2006.09.014.

Westlake, D. W.S., A. Jobson, R. Philippe, and F. D. Cook. 1974. "Biodegradability and Crude Oil Composition." Canadian Journal of Microbiology 20 (7): 915-28. https://doi.org/10.1139/m74-141.

Wirth, Roland, Etelka Kovács, Gergely Maráti, Zoltán Bagi, Gábor Rákhely, and Kornél L. Kovács. 2012. "Characterization of a Biogas-Producing Microbial Community by Short-Read next Generation DNA Sequencing." Biotechnology for Biofuels 5: 1-16. https://doi.org/10.1186/1754-6834-5-41.

Yao, Shuo, Jinren Ni, Qian Chen, and Alistair G L Borthwick. 2013. “Bioresource Technology Enrichment and Characterization of a Bacteria Consortium Capable of Heterotrophic Nitrification and Aerobic Denitrification at Low Temperature." Bioresource Technology 127: 151-57. https://doi.org/10.1016/j.biortech.2012.09.098.

Ying, G, Y Xing, Z Li, J Pan, and X Kuang. 2010. "Advantages of Psychrophiles in Improving Bio-Treatment Efficiency of Small Size Constructed Wetlands During Cold Weather" 29 (1): 25-33.

https://doi.org/10.1002/ep

.Yu, Lintang, Zhongya Tang, Li Feng, and Junjie Ji. 2020. “Engineering Application of Ecological Lake Purification Tailwater from Sewage Plant in Vein Industrial Park" 02026: 1-5.

Zeng, Jin, Yuqing Lin, Dayong Zhao, Rui Huang, Huimin Xu, and Congcong Jiao. 2019. "Seasonality Overwhelms Aquacultural Activity in Determining the Composition and Assembly of the Bacterial Community in Lake Taihu, China." Science of the Total Environment 683: 427-35. https://doi.org/10.1016/j.scitotenv.2019.05.256.

Zhang, Bo, Xiangyang Xu, and Liang Zhu. 2018. "Activated Sludge Bacterial Communities of Typical Wastewater Treatment Plants: Distinct Genera Identification and Metabolic Potential Differential Analysis." AMB Express 8 (1). https://doi.org/10.1186/s13568-018-0714-0.

\section{Figures}




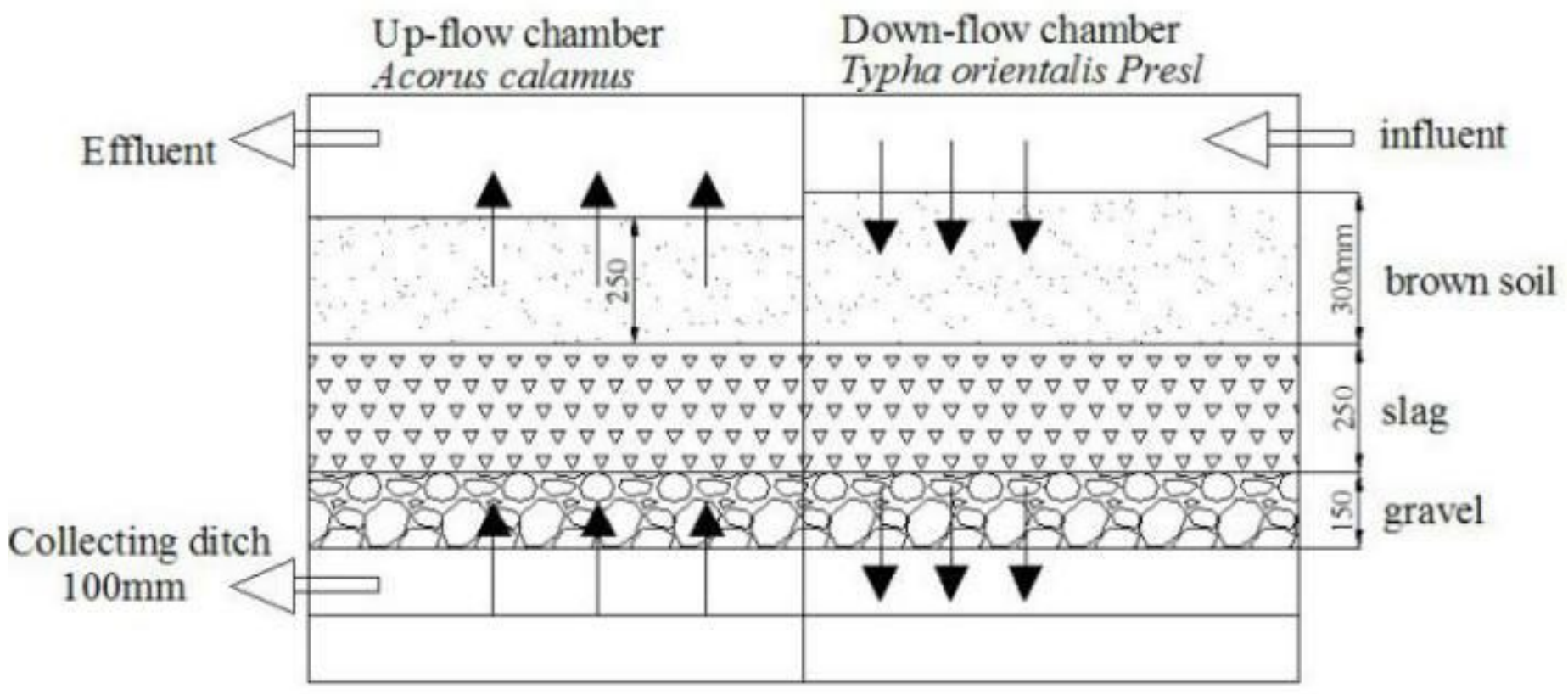

\section{Figure 1}

Schematic Diagram of the Vertical-flow Constructed Wetland System 

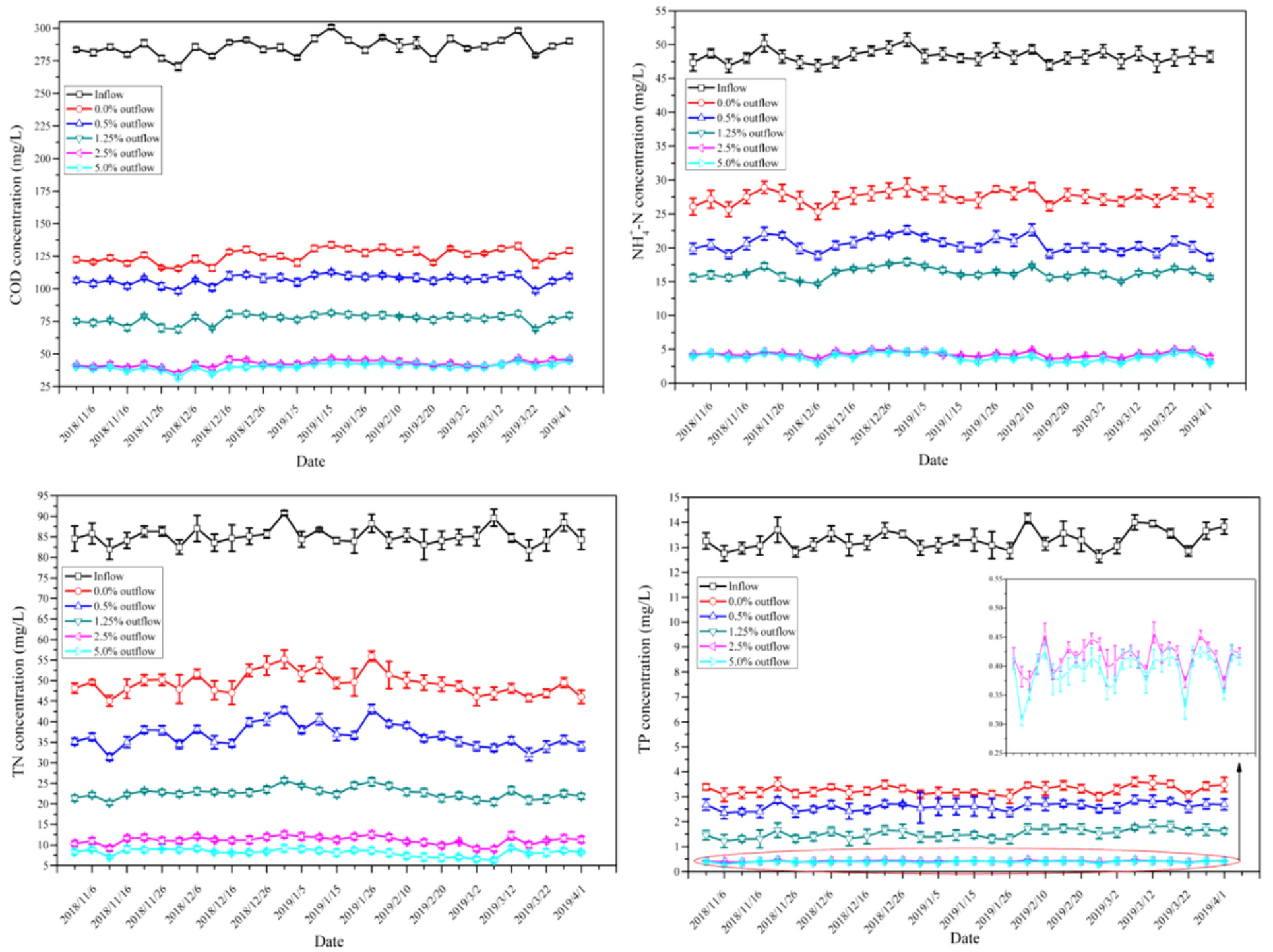

Figure 2

COD, NH4+-N囚TN and TP concentration in inflow and outflow with different dosages of mixed bacteria in the vertical flow wetland 

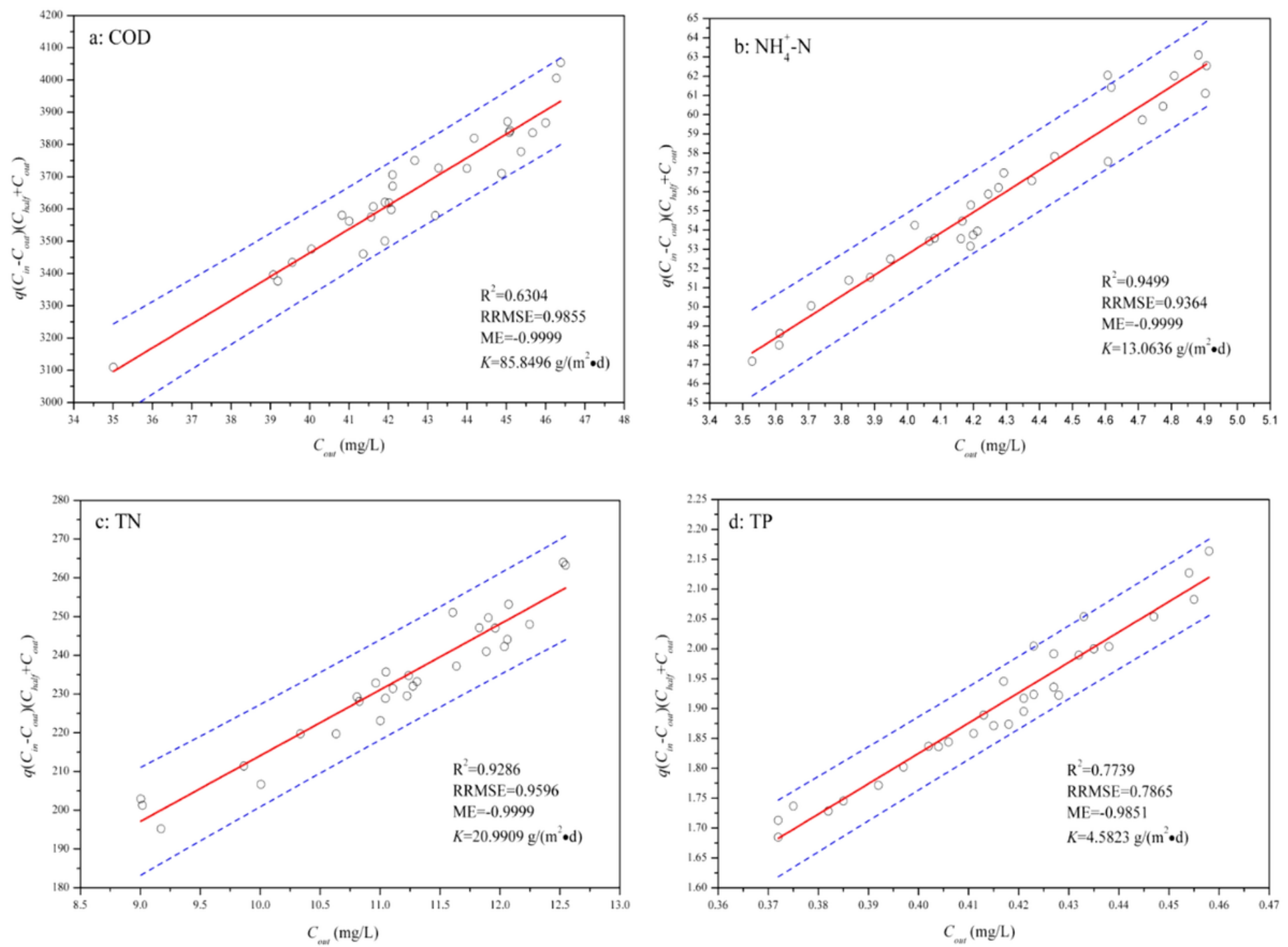

Figure 3

Monod kinetics regression between inflow and outflow COD, NH4+-N, TN and TP values in the vertical flow wetland. 


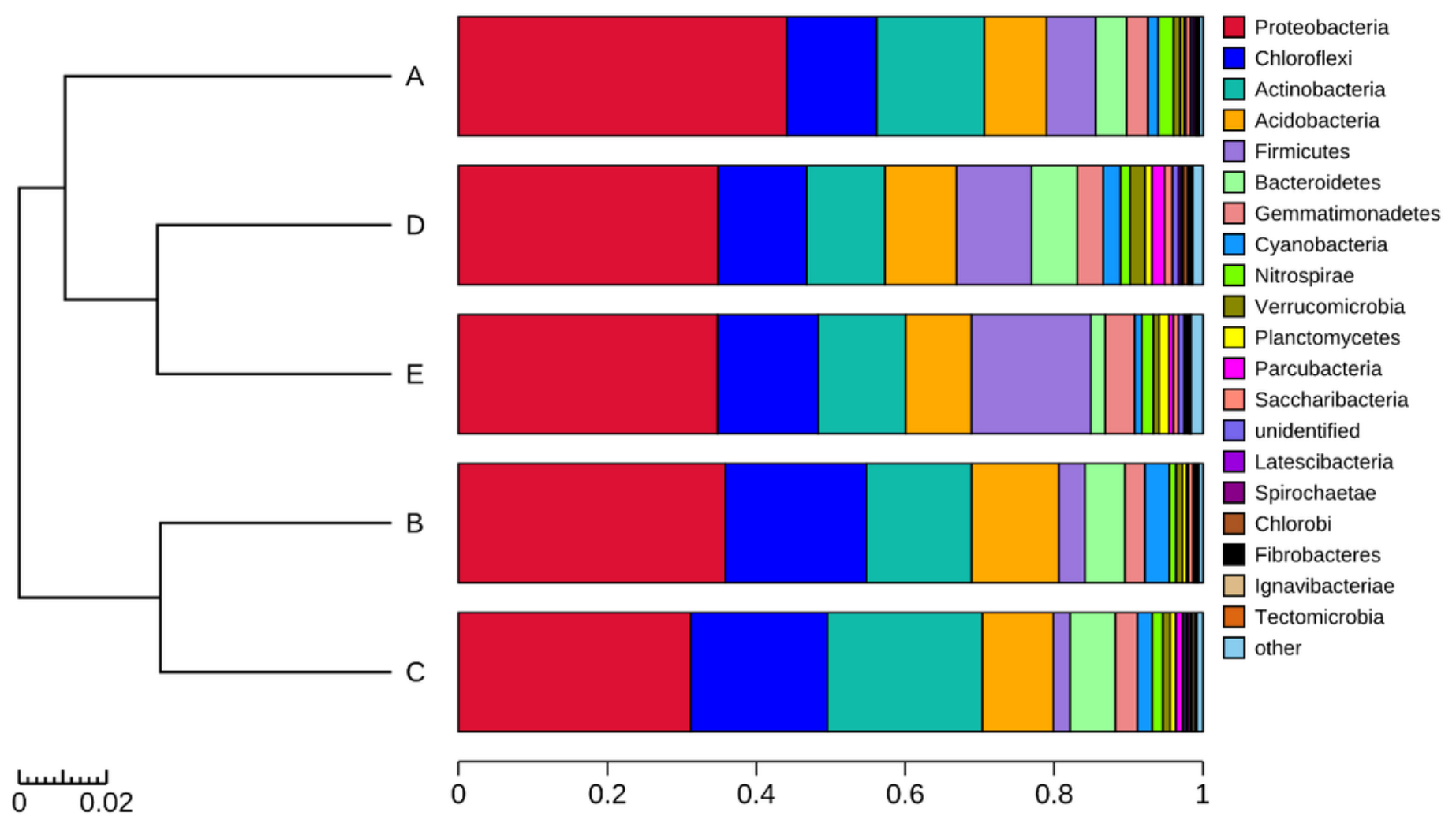

Figure 4

Relative ratio of the dominant bacteria at phylum level in different vertical flow wetlands (On the left is the hierarchical cluster analysis among samples, and on the right is the histogram of the community structure of the samples. The abscissa is the relative abundance of species in the sample, and the ordinate is the sample name.) 


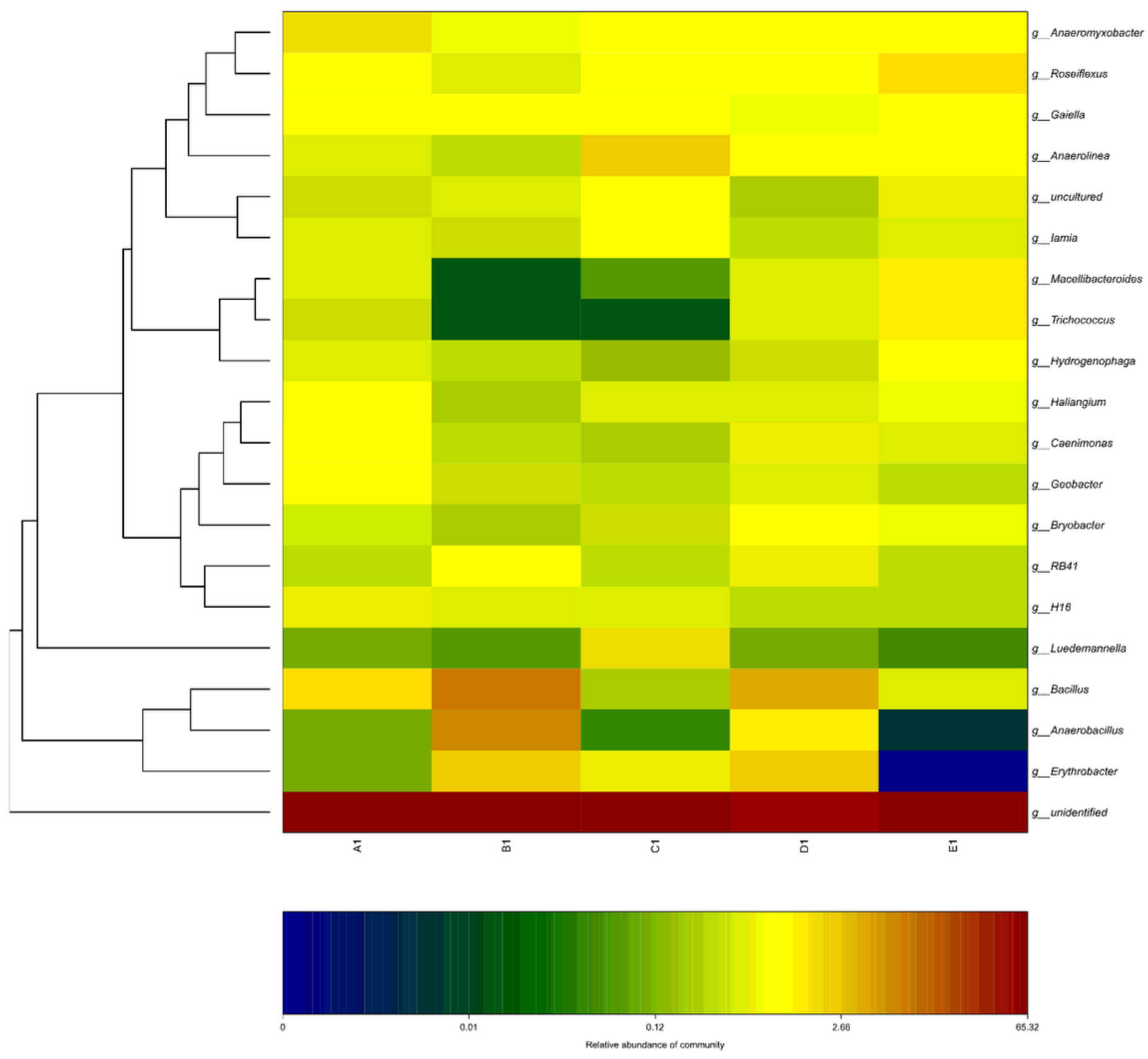

\section{Figure 5}

Thermal map analysis at genus level in different vertical flow wetland samples (On the left is the relationship clustering analysis of species. The abscissa is the genus of the sample, the ordinate is the species, and the color depth represents the abundance of the species. Only the dominant species at the top are shown here.) 